\title{
Forecasting China's food grain demand 2021-2050 with attention to balanced dietary and fertility policies
}

\section{Xiuli Liu ( $\nabla$ xiuli.liu@amss.ac.cn )}

Academy of Mathematics and Systems Science, Chinese Academy of Sciences, Beijing, China.

\section{Yuxing Dou}

Academy of Mathematics and Systems Science, Chinese Academy of Sciences, Beijing, China.

\section{Dabo Guan}

Department of Earth System Sciences, Tsinghua University, Beijing, China

\section{Geoffrey J.D. Hewings}

University of Illinois at Urbana-Champaign, IL, USA

\section{Shouyang Wang}

Academy of Mathematics and Systems Science, Chinese Academy of Sciences, Beijing, China.

\section{Research Article}

Keywords: food grain demand, forecasting, population structure, fertility policies, balanced diet

Posted Date: July 1st, 2021

DOl: https://doi.org/10.21203/rs.3.rs-675464/v1

License: (c) (i) This work is licensed under a Creative Commons Attribution 4.0 International License. Read Full License 


\title{
Forecasting China's food grain demand 2021-2050 with
} attention to balanced dietary and fertility policies

\author{
Xiuli Liu ${ }^{1,2,3 凶}$ Yuxing Dou ${ }^{1,3} \quad$ Dabo Guan $^{4}$
}

Geoffrey J.D. Hewings ${ }^{5} \quad$ Shouyang Wang ${ }^{1,2,3}$

\begin{abstract}
The estimation of China's future food grain demand has become vital input for designing grain security measures. Addressing the population's age-gender and urban-rural structures under three fertility policies scenarios together with concerns for balanced diets, we established a multifactor driven model to forecast China's food grain demand (including staple food grain and feed grain) during 2021-2050. The three scenarios are as follows; the two-child fertility policy for couples when either the husband or the wife is from a single-child family (scenario 1); universal two-child policy (scenario 2), and no limitations on the number of children (scenario 3). The results show that in scenario 3, China's food grain demand would peak in 2030 at about 329.3 million tons, about 3.7 million tons higher than that in scenario 2, and 104.7 million tons lower than that estimated with the traditional per capita method. These findings indicate that the demographic transition for fertility policy adjustment is not the main impacting factor of China's food grain security from 2021 to 2050 . We might overestimate food grain demand by about 15 percent if we ignored each agegender and urban-rural structure of the population. Then it may lead to an oversupply of grain and accumulation of stocks, which would generate about 1 billion RMB annual inventory cost burden. An important complement to the demographic strategy would come from the adoption of the proposed Dietary Guideline for Chinese Residents (2019). It can make people much healthier and save about 7.5 percent of China's food grain consumption, reducing the pressure scarce supplies of water and land in the country.
\end{abstract}

Food security means a sufficient supply of foods and nutrients (FAO,1996), which indicates one needs a diverse, balanced diet containing various foods, such as those rich in vitamins, iron, and zinc. Close to 750 million - or nearly one in ten people in the world in 2019- were exposed to severe levels of food insecurity. The majority of the world's undernourished - 381 million - are still found in Asia. At the global level, the prevalence of food insecurity at a moderate or severe level, and severe level only, is higher among women than men. The gender gap in accessing food increased from 2018 to 2019. If recent trends continue, the number of people affected by hunger will be 9.8 percent of the population by 2030 , even without considering the potential impacts of the COVID-19 pandemic (FAO, 2020).

China is the most populous country and the largest food consumer in the world. During 2013-2019, China's soybean, rice consumption accounted for about $30 \%$ of the total

\footnotetext{
${ }^{1}$ Academy of Mathematics and Systems Science, Chinese Academy of Sciences, Beijing, China.

${ }^{2}$ Center for Forecasting Science, Chinese Academy of Sciences, Beijing, China.

${ }^{3}$ University of Chinese Academy of Sciences, Beijing, China. 『e-mail: xulli.liu@amss.ac.cn

${ }^{4}$ Department of Earth System Sciences, Tsinghua University, Beijing, China

${ }^{5}$ University of Illinois at Urbana-Champaign, IL, USA
} 
world consumption, respectively. The proportion of corn was about $25 \%$, and for wheat, the ratio was in the range of $15 \%-20 \%$ (see figure 1 ). China's food security has been a global issue, especially since the book Who Will Feed China? (Brown, 1995) was published.

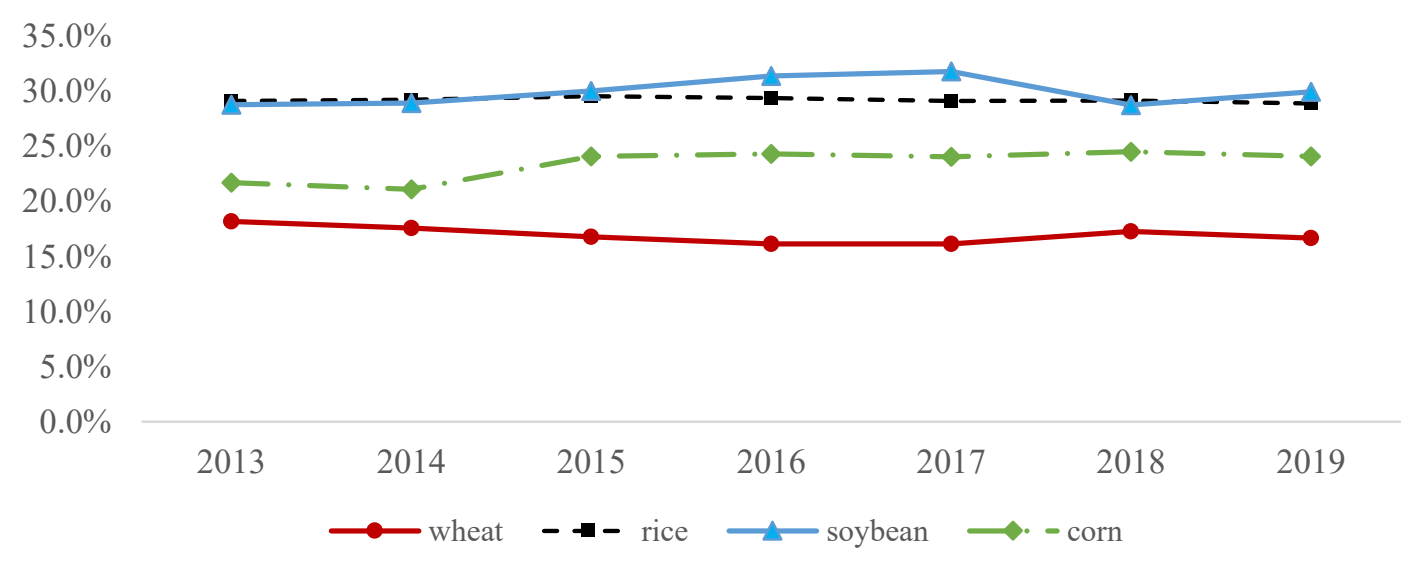

Data source: FAOSTAT

Figure 1. The proportion of China's grain consumption in the world's grain consumption, 2013-2019.

Meeting the demand for foods has always been the core of China's agricultural policy (Sheng and Song, 2019). China has made remarkable progress in achieving rapid growth in grain production since 1978 (Huang et al., 1999; Chen and Lu, 2019). In 2007, China's grain output reached a level of 500 million tons compared to 305 million tons in 1978, and the self-sufficiency percentage was more than $95 \%$. Since 2013 , the grain output had always remained above 600 million tons (figure 2). With a rapid increase in the consumption of animal foods and vegetable oils after 2007, grain consumption grew remarkably, and the self-sufficiency continuously declined to $83.7 \%$ in 2017 (NBSC, 2018; Anderson and Strutt, 2014). China's import of grain was more than 100 million tons after 2015 (figure 2). From 2010 to 2019, China had always been the largest soybean importing country, and its volume was far more than that of other countries. In 2020, China's soybean import was 1003.3 million tons, increasing 13.3\% from 2019.

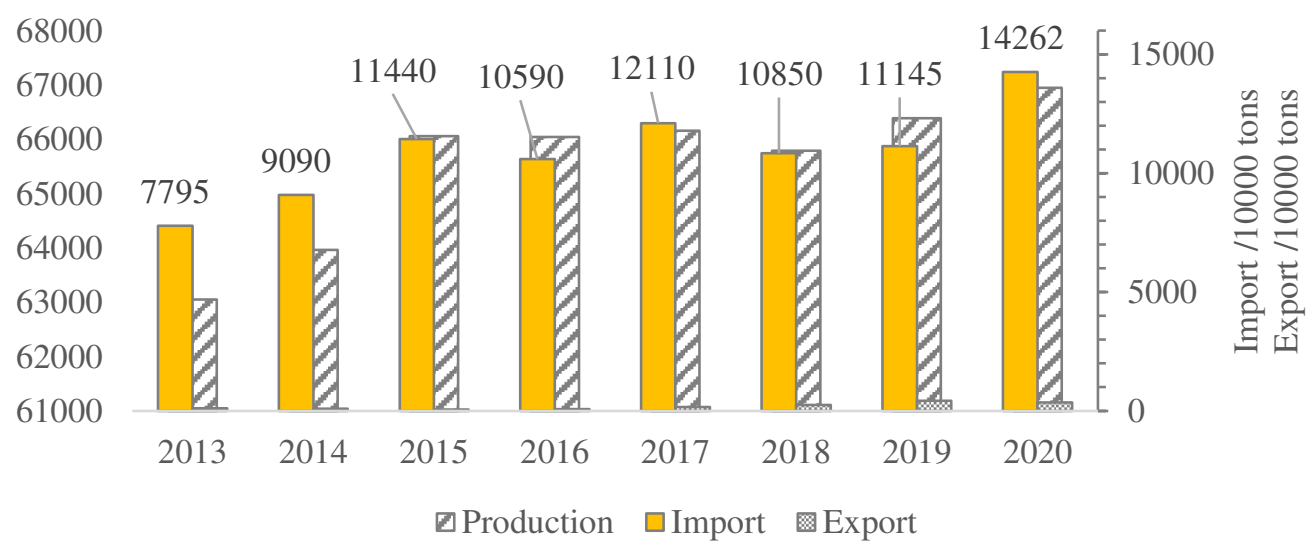

Figure 2. Grain production, imports and exports in China (unit:10000 tons) 
To the structure of China's grain consumption, the proportion of feed grain increased from $38.8 \%$ in 2013 to $43.0 \%$ in 2019 . And the ratio of staple food grain decreased from $32.6 \%$ in 2013 to $27.9 \%$ in 2019 . The proportions of seed grain, industrial grain, and the other were relatively stable during 2013-2019, ranging between $28.5 \%-30.3 \%$ (figure 3).

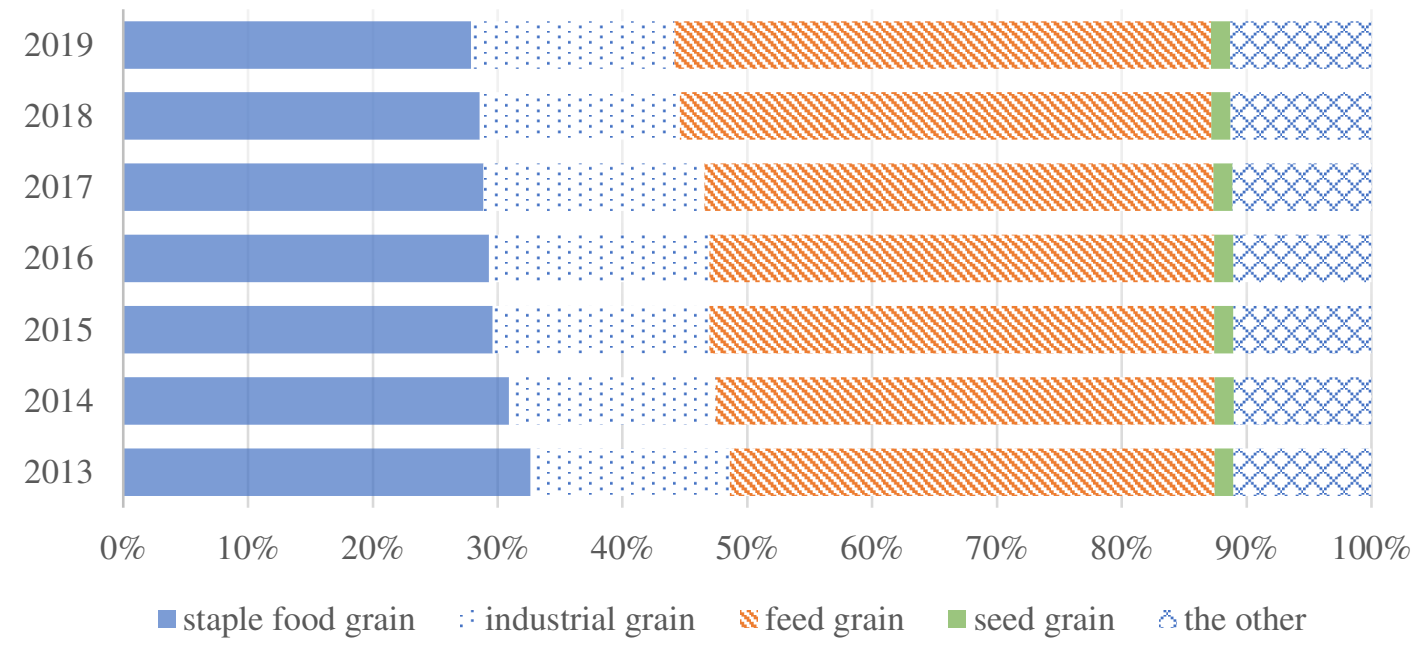

Data source: FAOSTAT

Figure 3. The consumption structure of grain in China during 2013-2019

Borlaug and Dowswell (1993) called for assessing the feasibility of maintaining global cereal production per capita in the next half-century. Before doing so, the food and feed resources per capita needed to provide a balance diet as a global average need to be estimated (Conway, 1997). Most existing research about food demand has focused on staple foods, such as wheat, rice, soybeans, and maize (e.g., Lobell et al., 2008; Müller et al., 2009; Rosenzweig et al., 2014). Although more recent studies have been concerned with a greater variety of foods (e.g., Ge et al., 2021; Macdiarmid et al., 2018; Ruiter et al., 2018; Nair et al., 2016). This paper focuses on staple food grain and feed grain, referred to as food grain that currently accounts for about $70 \%$ of the total grain demand in China.

As one of the main impacting factors of food grain demand, China's population structure is undergoing significant changes due to accelerated urbanization, increased aging, adjusted fertility policies and general increases in disposable income (Liu, 2018; Chen and Lu, 2019; Hovhannisyan et al., 2019). By around 2030, China's population is expected to grow to its peak of 1438 million (Liu and Liu, 2018). According to FAO data, the caloric demand of one person aged 17-18 reaches the highest average value and then shows a downward trend with individual age. The caloric demand of one person aged $60-69$ is $70.3 \%$ of the highest value, and to a person aged $80-89$, the ratio further decreases to $49.9 \%$ on average. The caloric demand of males is usually more than that of females.

Food consumption and nutrition are closely interlinked and can affect diet quality in different ways, potentially leading to undernutrition as well as overweight and obesity. The change in the dietary patterns of households is progressing at a rapid rate (Vecchia and Majem, 2015; Gouel and Guimbard, 2019; Liu et al., 2019). The rising incomes of 
rural and urban residents are among the main reasons (Vasileska and Rechkoska, 2012; Popkin et al., 2012). The Chinese diet has an inadequate intake of dairy products and the excessive intake of staple foods and meats (Han et al., 2020). From 1984 to 2017, the demand from Chinese residents for staple foods is decreasing, while the demand for processed foods and supplementary foods is increasing, and it is expected that the consumption of meat and dairy products will continue to rise for a long time ( $\mathrm{Lv}$ et al., 2017; Xin and Li, 2018).

Residents are beginning to pay more attention to the balanced dietary structure (Zheng et al., 2016; Zhang et al., 2016; Huang, 2018). Chen et al. (2018) and Zhang et al. (2019) concluded that Chinese citizens' principal and ultimate concern was a high-quality diet. The Chinese Nutrition Society had issued Dietary Guidelines for Chinese Residents to popularize nutrition knowledge and to guide people in achieving a balanced diet. Dietary Guideline for Chinese Residents (2019) (hereafter referred to as DGCR 2019) is the latest nutrition standard in China, which has some adjustments from the last version in 2016 (Li et al., 2016). DGCR 2019 is designed to meet the nutritional health and basic needs of Chinese residents; it recommends $250-400 \mathrm{~g}$ of cereals, potatoes, and beans, 50-100g of fish and shrimp, 50-75g of livestock and poultry meat, $300 \mathrm{~g}$ of milk and dairy products, and 25-50g of eggs, etc. per day for Chinese aged 15-50. The guide calls on everyone to improve his/her diet and eat more fruits, vegetables, eggs, milk, and less meat or cereals. If the DGCR 2019 is popularized, what will be the impact on China's food grain demand from a macro perspective? Policymakers need this information and can also draw on studies such as Gerbens-Leenes and Nonhebel (2002), (Hovhannisyan and Gould(2014), Hovhannisyan and Devadoss (2017) and Liu et al.(2019).

Most existing research on food grain demand focused on energy consumption (calories) (Cheng and Chen, 1998; Ma and Niu, 2009; Xin et al., 2015). However, given data limitations, few of these studies had fully considered the impacts of each age-gender structure of the population on grain demand, essential factors that directly affect food demand (Wu, 2011; Xiang et al., 2013; Liu et al., 2016). Furthermore, little research has been conducted to provide a detailed analysis of food grain demand from the perspective of the residents' dietary structure and nutrient intake status (Luo, 2008; Tang and Li, 2012).

In fact, at present, a macro estimation that measures the overall national food grain demand according to the latest DGCR is lacking. The provision of this information would enable a better understanding of the general change trend of food grain demand in the whole country, thus bringing scientific suggestions for improving food grain supply and developing appropriate policies to guide residents' diet. For these reasons, we established a multi-factor driven model to forecast China's food grain demand (including staple food grain and feed grain) during 2021-2050, with full consideration of the nutritional health standards of the residents, each age-gender structure, and urban and rural structure of them.

\section{Results}

\section{The Standard Person Consumption Coefficient (SPCC)}


We applied equations in Table 1 for estimating $B M R_{\mathrm{ik}}$ from bodyweight. Then with equations (1)-(2), the values of $\delta_{\mathrm{ik}}$ for Chinese males and females at different ages were obtained (see Figure 4).

Table 1. Equations for estimating $B M R$ from body weight

\begin{tabular}{|c|c|}
\hline Age (Years) & $B M R_{\mathrm{ik}}(\mathrm{MJ} / \mathrm{day})$ \\
\hline \multicolumn{2}{|l|}{ Males } \\
\hline$<\mathbf{3}$ & $0.2550 * A W_{\mathrm{ik}}-0.14$ \\
\hline 3-9 & $0.0937 * A W_{\mathrm{ik}}+2.15$ \\
\hline $10-17$ & $0.0769 * A W_{\mathrm{ik}}+2.43$ \\
\hline 18-29 & $0.0669 * A W_{\mathrm{ik}}+2.28$ \\
\hline $30-60$ & $0.0592 * A W_{\mathrm{ik}}+2.48$ \\
\hline$>60$ & $0.0563 * A W_{\mathrm{ik}}+2.15$ \\
\hline \multicolumn{2}{|l|}{ Females } \\
\hline$<\mathbf{3}$ & $0.2460 * A W_{\mathrm{ik}}-0.0965$ \\
\hline $3-9$ & $0.0842 * A W_{\mathrm{ik}}+2.12$ \\
\hline $10-17$ & $0.0465 * A W_{\mathrm{ik}}+3.18$ \\
\hline 18-29 & $0.0546^{*} A W_{\mathrm{ik}}+2.33$ \\
\hline $30-60$ & $0.0407 * A W_{\mathrm{ik}}+2.90$ \\
\hline$>60$ & $0.0424 * A W_{\mathrm{ik}}+2.38$ \\
\hline
\end{tabular}

* Note: $A W_{\text {ik }}$ is expressed in $\mathrm{kg}$. $B M R$ equations in table 1 were sourced from Henry (2005).

1.2

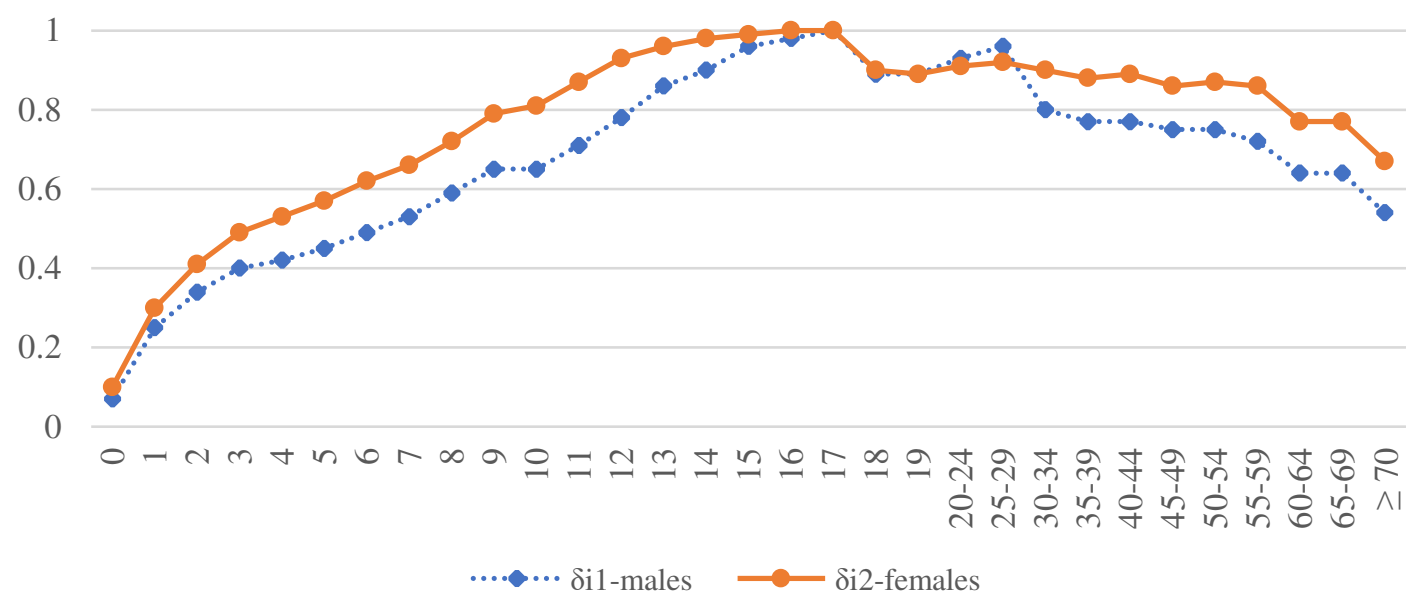

Figure 4. The estimated $\delta_{\mathrm{ik}}$ for Chinese males and females at different ages

\section{Forecasted Chinese Population by Age-Gender}

Liu and Liu (2018) developed by age and gender based population projections for China with the cohort-component method. We used the results in the 3 scenarios. China's three-child policy was announced on 1st June 2021 and is expected to maximize the population's role in driving economic and social growth and address the risks of a downward trend in fertility, according to the country's health authority. Liu and Liu (2020) indicated that even if the two-child policy is further relaxed, it will exert little influence on fertility choice. It can be supposed that scenario 3 will have the most 
consistent with China's actual population structure and size in the future.

In scenario 3, China's population is expected to grow to its peak of 1457.6 million in 2030; the population size would be 1444.9 million in 2040 and 1413.8 million in 2050 (figure 5); the aging rate (which is the proportion of elderly persons aged $\geqslant 60$ years accounts for the total size of the population) would reach $26.4 \%$ in $2030,31.7 \%$ in 2040 and $36.4 \%$ in 2050. Compared with scenario 2, the population peak would increase by about $1.3 \%$ in scenario 3 , and the aging rate would decrease 0.4 percentage points in 2030, 0.7 percentage points in 2040, and 1.3 percentage points in 2050 in scenario 3.

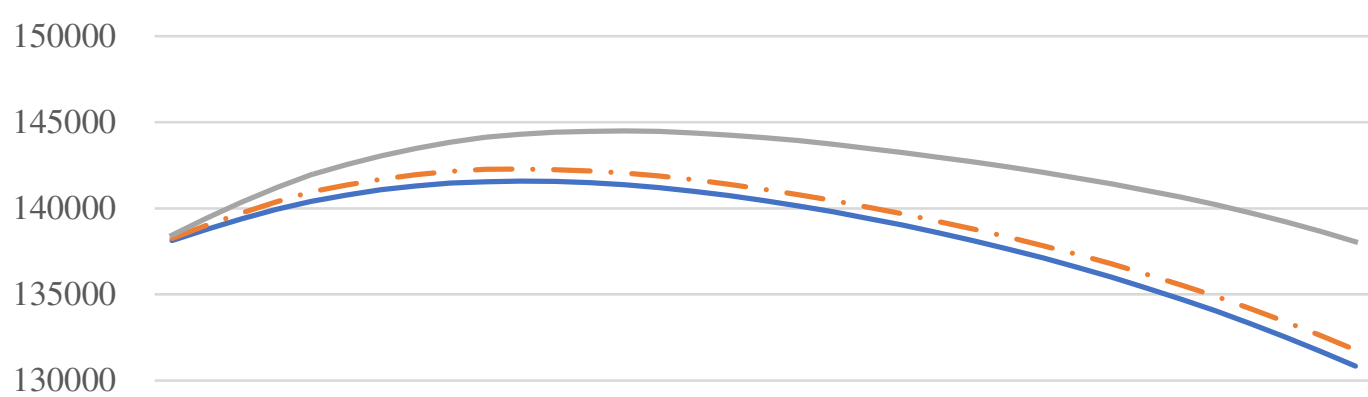

125000

120000

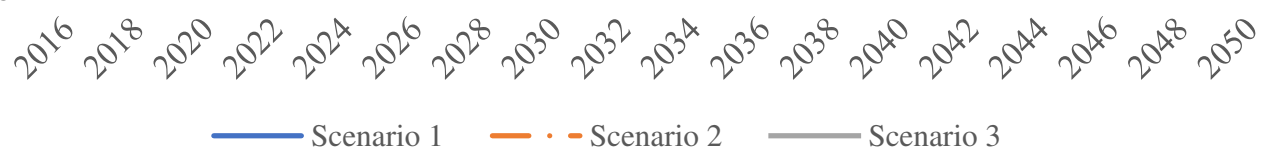

Source: Liu and Liu (2018)

Figure 5. The predicted size of the population in China in 3 scenarios

Furthermore, in scenario 3, the male aging rate would be $23.2 \%$ in $2030,28.6 \%$ in 2040 , and $31.9 \%$ in 2050 (Figure 6.a), while the females aging rate would be $26.1 \%$ in 2030 , $32.5 \%$ in 2040 , and $37.2 \%$ in 2050 (Figure 6.b). The aging rate of females is most commonly greater than that of males in the same year.

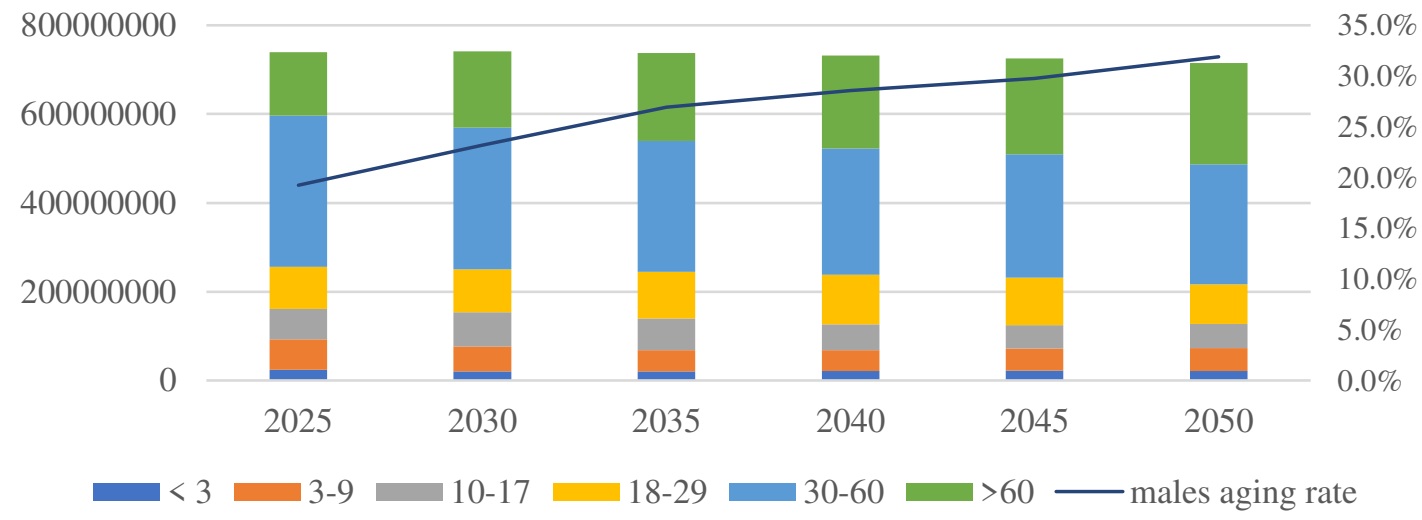

$(6 . a)$ 
180

(6.b)

Figure 6. Males (a) and females (b) in different age group and their aging rates in China in Scenario 3

For the population younger than 30 years old, the ratio of males to females would be greater than 1.1 over the period 2025-2050. In particular, for the cohort aged 18-29, the ratio of males to females would be 1.18 in 2030 in scenario 3 (figure 7). The imbalance of males and females will bring many social problems and the gender structure will impact the demand for food grain.

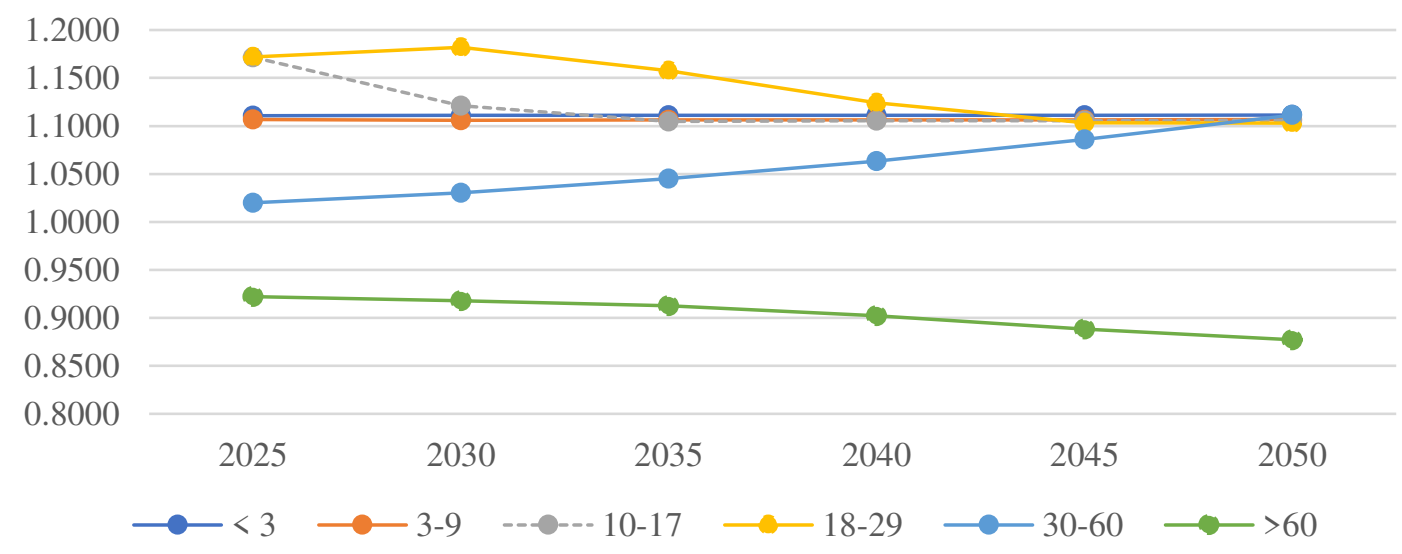

Figure 7. The ratio of males and females in different age groups in scenario 3

\section{Forecasted Urbanization Rate}

There are apparent differences in income levels and consumption habits of urban and rural residents. The development experience of Asian high-income countries from the 1970s to 1990s showed that the increase of urban population and livestock consumption meant that more food grain (especially feeding grain) was consumed. Further, addressing the urban and rural structure of the population can improve the forecasting accuracy of food grain demand. China's urbanization rate (means the proportion of urban permanent population in total permanent population) has risen steadily every year, from $17.92 \%$ in 1978 to $63.89 \%$ in 2020 . The development of the urbanization rate in various countries indicates that it presents an elongated S-type curve. The urbanization rate increases rapidly after the first inflection point, slowing down obviously after the second inflection point. Based on Japanese and German experience, China's urbanization process may slow down after reaching 65\%-70\%; at present, China is still 
in an accelerated period of urbanization. Drawing on the work of Jian and Huang (2010) to predict China's urbanization rate during the accelerated period suggest that China would reach the second inflection point around 2030; this was estimated with equations (3)-(6).

It is estimated that China's urbanization rate would be $64.11 \%$ in 2021 and $73.69 \%$ in 2030 (figure 8). With the method proposed by Zeng et al. (2013), we assumed an average annual growth rate of 0.5 percentage points from 2030 to 2050 . The urbanization rate in 2050 is estimated to be $83.69 \%$ (figure 8 ). The prediction result of China's urbanization rates in this paper is consistent with the judgment of several studies such as RDR (2020) and UDE (2019).

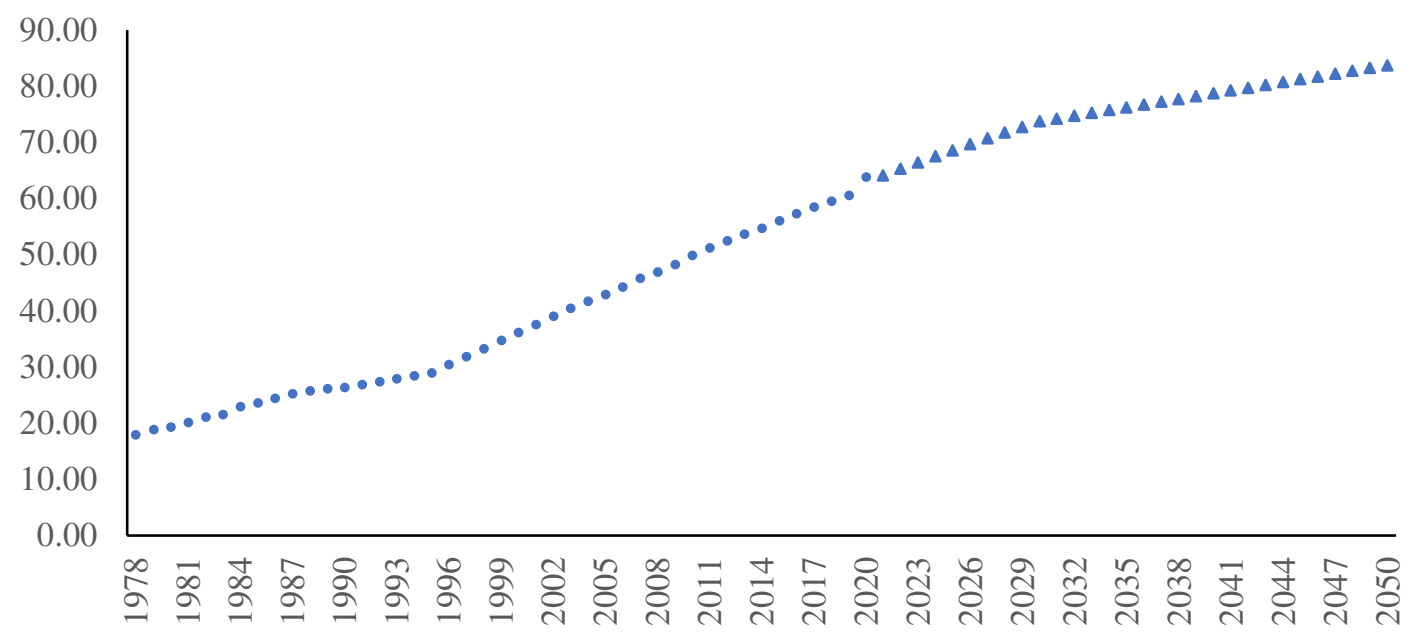

Figure 8. The urbanization rate in China from 1978 to $2050(\%)$

(1978-2020 data is sourced from National Bureau of Statistics of China)

\subsection{Forecasted per Capita Daily Food Grain Demand by an Adult based on DGCR 2019}

Using the DGCR 2019, the per capita food grain demand in the balanced dietary pattern is divided into high, medium, and low levels. The conversion coefficient of livestock products to food grain consumption was estimated according to the method proposed by Chen and $\mathrm{Lu}$ (2019), and the results are shown in table 2.

Table 2. The grain consumption conversion coefficient of different kinds of livestock products

\begin{tabular}{cc}
\hline Livestock products & The grain consumption conversion coefficient \\
\hline Pork & 2.8 \\
Beef and Mutton & 1.0 \\
Poultry & 2.0 \\
Eggs & 1.7 \\
Milk & 0.3 \\
Fish & 0.9 \\
\hline
\end{tabular}

Using the method of Tang and Li (2012), the average food consumption structure in China during 2014-2018 was estimated with data from FAOSTAT (2014-2018); the results are shown in table 3 . 
Table 3. The average food grain consumption structure in China during 2014-

2018

\begin{tabular}{|c|c|c|c|}
\hline Varieties & Food grain items & $\begin{array}{c}\text { Average annual food } \\
\text { consumption 2014- } \\
2018 \text { (1000 tons) }\end{array}$ & Proportion $(\%)$ \\
\hline \multirow[t]{6}{*}{ Grains } & Cereal & 271095 & 81.0 \\
\hline & (Wheat) & 92106 & 34.0 \\
\hline & (Rice) & 168651 & 62.2 \\
\hline & (Maize) & 10338 & 3.8 \\
\hline & Pulses & 1991 & 0.6 \\
\hline & Tubers & 61748 & 18.4 \\
\hline \multirow[t]{6}{*}{ Meats } & $\begin{array}{l}\text { Pig meat, bovine meat, } \\
\text { and mutton }\end{array}$ & 66332 & 75.3 \\
\hline & (Pig meat) & 54176 & 81.7 \\
\hline & (Bovine meat) & 7148 & 10.8 \\
\hline & (Mutton) & 5008 & 7.5 \\
\hline & Poultry & 20249 & 23.4 \\
\hline & Other & 1473 & 1.7 \\
\hline \multirow[t]{4}{*}{ Aquatic products } & Crustaceans & 6386 & 13.4 \\
\hline & Freshwater fish & 24985 & 52.4 \\
\hline & Marine fish & 2102 & 4.4 \\
\hline & $\begin{array}{l}\text { Molluscs aquatic } \\
\text { products }\end{array}$ & 14178 & 29.8 \\
\hline \multirow[t]{2}{*}{ Milk } & Cow milk & 32548 & 88.1 \\
\hline & Other & 4380 & 11.9 \\
\hline \multirow[t]{2}{*}{ Eggs } & Chicken egg & 23078 & 84.4 \\
\hline & Other & 4251 & 15.6 \\
\hline \multirow[t]{2}{*}{ Vegetable } & Tomato & 48379 & 9.8 \\
\hline & Other & 443234 & 90.2 \\
\hline \multirow[t]{2}{*}{ Fruit } & Apple & 30574 & 22.0 \\
\hline & Other & 108375 & 78.0 \\
\hline \multirow[t]{2}{*}{ Pulse and nut } & Pulse & 1991 & 34.6 \\
\hline & Nut & 3756 & 63.4 \\
\hline \multirow[t]{2}{*}{ Oil } & Animal fats & 11852 & 79.8 \\
\hline & Vegetable oils & 2996 & 20.2 \\
\hline
\end{tabular}

Using the estimates in tables 2 and 3, we calculated the corresponding food grain conversion coefficients of different foods under the assumption of a balanced diet. These results are shown in table 4. To the food consumption data from FAOSTAT, food waste in household was not accounted for, this will lead to a lower estimation of food consumption. In Southeast Asia, the percentage of food waste in household consumption (Gustavsson et al., 2011) is listed in table 4. We used these data as the percentage of food waste in China's household consumption. percentage of food waste in household consumption in Southeast Asia 


\begin{tabular}{ccc}
\hline Foods & $\begin{array}{c}\text { The conversion } \\
\text { coefficient }\left(\boldsymbol{V}_{\boldsymbol{i}}\right)\end{array}$ & $\begin{array}{c}\text { Percentage of foods waste in } \\
\text { household consumption }\left(\boldsymbol{C}_{\boldsymbol{i}}\right)\end{array}$ \\
\hline Cereal, tubers and beans-1 & 1.0 & $3 \%$ \\
\hline Vegetable-2 & 0.0 & $7 \%$ \\
\hline Fruit-3 & 0.0 & $7 \%$ \\
\hline Fish and shrimp-4 & 0.9 & $2 \%$ \\
\hline Meat and poultry-5 & 2.3 & $4 \%$ \\
\hline Eggs-6 & 1.7 & $1 \%$ \\
\hline Milk and Dairy-7 & 0.3 & $1 \%$ \\
\hline Pulse and Nut-8 & 1.0 & $1 \%$ \\
\hline Oil-9 & 0.15 & $1 \%$ \\
\hline
\end{tabular}

Using equation (7), with the values of $V_{i}, C_{i}$ from table 4 and $L_{i j}$ from table 5, we can estimate $G_{i j}$; the results are shown in table 5. Equation (8) provides the values of $A G_{1}=215.8 \mathrm{~kg}, A G_{2}=275.0 \mathrm{~kg}, A G_{3}=334.2 \mathrm{~kg}$ and $A G_{4}=259.3 \mathrm{~kg}$.

Table 5. The per capital daily food grain demand of China's residents (Unit: g)

\begin{tabular}{ccccccccc}
\hline Items & $\boldsymbol{L}_{\boldsymbol{i 1}}$ & $\boldsymbol{L}_{\boldsymbol{i 2}}$ & $\boldsymbol{L}_{\boldsymbol{i} \mathbf{3}}$ & $\boldsymbol{L}_{\boldsymbol{i} \mathbf{4}}$ & $\boldsymbol{G}_{\boldsymbol{i \mathbf { 1 }}}$ & $\boldsymbol{G}_{\boldsymbol{i} \mathbf{2}}$ & $\boldsymbol{G}_{\boldsymbol{i \boldsymbol { 3 }}}$ & $\boldsymbol{G}_{\boldsymbol{i 4}}$ \\
\hline Cereal, tubers and beans-1 & 250 & 325.0 & 400 & 358.7 & 257.7 & 335.1 & 412.4 & 369.7 \\
\hline Vegetable-2 & 300 & 400.0 & 500 & 260.9 & 0 & 0 & 0 & 0 \\
\hline Fruit-3 & 200 & 300.0 & 400 & 125.4 & 0 & 0 & 0 & 0 \\
\hline Fish and shrimp-4 & 50 & 75.0 & 100 & 32.4 & 45.9 & 68.9 & 91.8 & 29.7 \\
\hline Meat and poultry-5 & 50 & 62.5 & 75 & 99.5 & 119.8 & 149.7 & 179.7 & 238.4 \\
\hline Eggs-6 & 25 & 37.5 & 50 & 27.2 & 42.9 & 64.4 & 85.9 & 46.7 \\
\hline Milk and Dairy-7 & 300 & 300.0 & 300 & 33.4 & 90.9 & 90.9 & 90.9 & 10.1 \\
\hline Pulse and Nut-8 & 30 & 40.0 & 50 & 11.4 & 30.3 & 40.4 & 50.5 & 11.5 \\
\hline Oil-9 & 25 & 27.5 & 30 & 27.8 & 3.8 & 4.2 & 4.5 & 4.2 \\
\hline Sum & - & - & - & - & 591.3 & 915.7 & 753.6 & 710.5
\end{tabular}

In table $5, L_{i 4}$ was estimated with the average per capita daily food consumption of different categories from 2015 to 2019 from the China Statistical Yearbook data. We can see that $L_{54}$ is 1.3 times of $L_{53} . L_{14}, L_{94}$ are in the suggested range $\left(L_{11}, L_{13}\right)$ and $\left(L_{91}, L_{93}\right)$. While $L_{74}$ is only 0.1 times of $L_{71} . L_{84}$ is 0.4 times of $L_{81} . L_{34}$ and $L_{44}$ is 0.6 times of $L_{31}$ and $L_{41}$ respectively. These indicate that Chinese households consumed more meat and poultry, but their consumption of milk and dairy, pulse and nut, fruit, and vegetables was insufficient to accord with a recommended balanced diet.

\section{Forecasted China's Food Grain Demand in 3 Scenarios}

We took the high level of the food grain consumption based on the DGCR 2019, $334.2 \mathrm{~kg} /$ year, as the volume of food grain consumption of an urban male standard person with a balanced diet. According to the recommended dietary energy intake for Chinese residents, at age 18-50 years old, it is $11.3 \mathrm{MJ} / \mathrm{d}$ for males and $9.6 \mathrm{MJ} / \mathrm{d}$ for females (Chinese Nutrition Society, 2014), which means the energy demand of a female is $85.1 \%$ of that for a male on average. Then, the food grain demand for an urban female standard person was estimated to be $284.4 \mathrm{~kg} /$ year. According to Xin et al. (2015), the 
difference between urban and rural residents' per capita food grain consumption was about $45.7 \mathrm{~kg}$. Therefore, the food grain demand with a balanced diet of a standard person (male or female) in an urban and rural area can be estimated (table 6).

Table 6 . The estimated food grain demand of a standard person in an urban and rural area with a balanced diet (Unit: $\mathrm{kg} /$ year)

urban male $\left(u_{1}\right)$

334.2 urban female $\left(u_{2}\right)$

284.4 rural male $\left(r_{1}\right)$

288.5

rural female $\left(r_{2}\right)$

\section{7}

Using the estimates provided in table 6 , the demand for food grain with a balanced diet in China during 2021-2050 under the three fertility scenarios ( $s g d s$ ) can be estimated with equation (9); If the SPCC method was not applied, equation (10) was traditionally used to estimate the food grain demand with a balanced diet. If the actual dietary structure was kept in scenario $s$, the food grain demand $a g d_{s}$ was estimated with equation (11). The results are shown in table 7.

Table 7. The estimation results of China's food grain demand with balanced diet from 2021 to 2050 in three scenarios (unit: million tons)

\begin{tabular}{cccccccccc}
\hline Year & $s g d_{1}$ & $g d_{1}$ & $a g d_{1}$ & $s g d_{2}$ & $g d_{2}$ & $a g d_{2}$ & $s g d_{3}$ & $g d_{3}$ & $a g d_{3}$ \\
\hline 2021 & 316.7 & 413.1 & 365.1 & 318.5 & 417.3 & 368.7 & 319.6 & 420.2 & 371.3 \\
\hline 2025 & 319.6 & 418.2 & 367.1 & 322.6 & 420.4 & 369.0 & 324.7 & 428.6 & 376.2 \\
\hline 2030 & 320.5 & 420.3 & 366.2 & 325.6 & 422.4 & 367.9 & 329.3 & 434.0 & 378.1 \\
\hline 2035 & 316.3 & 417.7 & 362.6 & 323.2 & 419.5 & 364.1 & 328.6 & 434.4 & 377.0 \\
\hline 2040 & 309.5 & 412.8 & 357.0 & 317.9 & 414.7 & 358.6 & 325.0 & 433.3 & 374.7 \\
\hline 2045 & 301.1 & 405.3 & 349.3 & 311.3 & 407.8 & 351.4 & 320.4 & 431.3 & 371.6 \\
\hline 2050 & 291.2 & 395.2 & 339.3 & 303.4 & 397.9 & 341.5 & 314.6 & 427.2 & 366.7 \\
\hline
\end{tabular}

\section{Analysis of the Results}

Table 7 shows that $s g d_{3}$ would peak at 329.3 million tons in 2030 and decrease $24.1 \%$ compared with $g d_{3}$ in 2030. The maximum difference between $s g d_{3}$ and $g d_{3}$ would be 112.6 million tons in 2050, and the minimum difference would be 100.5 million tons in 2021. For the other two scenarios, the difference between $s g d$ and $g d$ would be in the range of 94.4-104.3 million tons. Each amount accounts for $14.1 \%$ and $15.6 \%$ of total China's grain production in 2020, respectively. It means that we may overestimate food grain demand by about 15 percent if we ignore the age-gender and urban-rural structure of the population. Thence, the estimates may lead to an oversupply of grain and accumulation of stocks, which will generate an inventory burden.

From table 7, we know that the value of agd is between $s g d$ and $g d$ each year. In scenario $3, a g d_{3}$ is about 50 million tons greater than $s g d_{3}$ during 2021-2050, which means that if all Chinese household adopt DGCR 2019 in scenario 3, about 50 million tons of food grain would be saved, which accounts for $7.5 \%$ of China's total grain production in 2020. The results indicate that we should promote DGCR 2019, since there would be a double dividend - a healthier population and a saving of about 7.5 percent of food grain consumption, reducing the scarcity pressure of water and land.

In table 7, in each year $s g d_{3}$ is greater than $s g d_{2}$ and $s g d_{2}$ is also larger than $s g d_{1}$ because of different fertility policies. Compared with $s g d_{2}, s g d_{3}$ would have increments of 2.1 
million tons in 2025, 3.7 million tons in 2030, and 11.2 million tons in 2050. $s g d_{3}$ is also greater than $s g d_{1}$ each year, with increments of 5.1 million tons in 2025, 8.8 million tons in 2030, and 23.4 million tons in 2050, which accounts for $0.76 \%, 1.31 \%$, and $3.50 \%$ of China's total grain production in 2020 respectively.

About 35\% of China's grain production was wasted annually around 2014 (Xinhua Net, 2014). The annual restaurant food waste in China was about 17-18 million tons in 2015 (Cheng et al., 2018), which is much higher than the annual increase in food grain demand due to demographic policy changes over the period 2021-2050. Hence, the shift in population size and structure caused by China's fertility policy adjustment is not the main factor that is influencing food grain demand from 2021 to 2050.

A sensitivity analysis is needed to estimate the impact of some uncertainty in the average weight of the population over 70 years; currently, these estimates are $63.5 \mathrm{~kg}$ for a male and 55.6kg for a female (Lv and Zhang, 2018). The effect of a $5 \mathrm{~kg}$ fluctuation of average weight over 70 years old on food grain demand is shown in table 8. In 2030, 2040 , and 2050, the proportion of the population over 70 years old would be $11.4 \%$, $17.1 \%$, and $21.3 \%$, respectively. The sensitivity analysis results show that if the fluctuation of average weight over 70 years old is within $5 \mathrm{~kg}$, the impact on food grain demand is less than $0.8 \%$. Therefore, we can accept the estimation of the average weight over 70 years old.

Table 8. Effect of average weight fluctuation of people over 70 years old on food grain demand

\begin{tabular}{cccccccc}
$\begin{array}{c}\text { Average weight over } \\
70 \text { years }\end{array}$ & 2021 & 2025 & 2030 & 2035 & 2040 & 2045 & 2050 \\
$\pm 5 \mathrm{~kg}$ & $0.27 \%$ & $0.34 \%$ & $0.39 \%$ & $0.49 \%$ & $0.62 \%$ & $0.72 \%$ & $0.76 \%$ \\
\hline
\end{tabular}

\section{Discussion}

There are BMR equations for Chinese people as a whole but not for the different age groups. Equations for estimating BMR of varying age groups in this paper were derived from Henry (2005), which were the latest equations we can find for the world population. But they are not designed especially for the Chinese population. We used the percentage of food waste data in Southeast Asia as the data for China since there have no such detailed data in China. In order to prevent food waste, ensure national food security, save resources, protect the environment, and promote sustainable economic and social development, a law on preventing food waste of the people's Republic of China has been formally implemented from April 29, 2021. Food waste in China should be decreased in recent years and the future. These may generate some uncertainty in the results. So far, we have only considered the average food intake for the different age-gender groups in China's urban and rural areas. We have not considered the preference of foods and different constitutions of the population across different regions in China. Further research will need to be conducted to address the spatial heterogeneity within China.

Although there is a considerable literature that has predicted China's grain demand, most of their results are very crude, e.g., ignoring dynamic change of age-gender 
composition of its population, not considering the need for a balanced diet and so forth. Table 9 shows the predictions for China's grain demand in 2020 and 2030. As their prediction models and parameters differ from each other, it is not surprising that their results are also different ( $\mathrm{Lv}$ and $\mathrm{Hu}$ 2012; Mi et al. 2013). Commonly, if the population's age structure and urban-rural structure were considered in the prediction model, the forecasted grain demand is smaller than those that ignored these factors. Results from this study confirm the need to address demographic differences and geographic location in generating forecasts.

Table 9. Forecasted results of China's grain demand in some literature

\begin{tabular}{llllll}
\hline & Methods & $\begin{array}{l}\text { Forecasted } \\
\text { year }\end{array}$ & $\begin{array}{l}\text { Population } \\
\text { age structure }\end{array}$ & $\begin{array}{l}\text { Urban- } \\
\text { rural } \\
\text { structure }\end{array}$ & $\begin{array}{l}\text { Forecasted China's } \\
\text { grain } \\
\text { (million tons) }\end{array}$ \\
\hline Gao (2004) & Time series & 2020 & no & no & 590 \\
\hline Tang (2012) & Balanced diet & 2020 & no & no & 567 \\
\hline Yuan (2017) & Balanced diet & 2020 & Yes & Yes & 480 \\
\hline Luo (2008) & Nutrition & 2020 & no & yes & 576 \\
\hline Zhang (2012) & CEMM & 2030 & no & yes & 610 \\
\hline Tang (2012) & Balanced diet & 2030 & no & yes & 586 \\
\hline Yuan (2017) & Balanced diet & 2030 & yes & yes & 560 \\
\hline
\end{tabular}

Compared with the traditional forecasting methods for food grain demand, this study developed a multi-factor driven model with additional factors such as age-gender structure, dietary nutrition standard, fertility policies, etc., in the forecasting methodology. These factors are common in the real world but difficult to incorporate into existing models. In addition, the adopted model includes a comprehensive list of foods and is linked to a dietary nutrition standard. The model can thus be used to identify which food may be in short supply to meet a balanced diet under different scenarios. Significantly, the model can be applied to evaluate the impacts of fertility policy on food grain demand which arouses the intense attention of the government, residents, and academics.

The multi-factor driven model developed in this paper will be a framework. There are many ways to extend the model in the future. Apart from age-gender, urban-rural structure, some other factors can affect food grain demand, such as COVID-19, climate change (Ye et al., 2013), region-specific inequality, etc. It can be easily adapted to implement additional factors to be built into the model later, which is beyond the scope of this study. Although prices are not explicitly incorporated in this model, the price mechanism to allocate commodities among residents was partially incorporated in the consumption and dietary preferences.

\section{Conclusions and suggestions}

First, the change of age-gender structure, especially the increase of the aging rate, will reduce the food grain demand and release the pressure on food grain security. Compared with results provided by more traditional methods, China has about 15 percentage points of slack space in planning its future food grain demand, which can 
save about 1 billion RMB in grain annual inventory costs. Furthermore, the structure of food grain demand we forecasted is different from that provided by the traditional method, and it will meet with the balanced dietary demand. China's grain production structure can be adjusted according to the forecasted results of food grain demand in the future.

Secondly, the results show that the change of population size and structure caused by the adjustment of China's fertility policies is not the main influencing factor of food grain demand from 2021 to 2050. This finding is in line with Song et al. (2021), who suggested that the one-child policy's relaxation is unlikely to significantly affect total grain consumption. Hence, there appears to be a significantly reduced concern about the effect of changes in family planning policy on food grain demand. Liu and Liu (2020) indicated that even if the two-child policy is further relaxed (such as to the threechild policy), it will exert little influence on fertility choice. Thus, pro-birth public policies, such as strengthening China's infrastructure and public facilities to support child-rearing (Li et al., 2019; Qian et al., 2020), free universal public schooling from the age of three, improving the average level of compulsory education, etc. should be combined to increase fertility rate.

Thirdly, we should promote the implementation of DGCR 2019. It can make people healthier and save about 7.5 percent of food grain consumption, which will release the scarcity pressure of water and land. Huang and Tian (2019) found that food accessibility contributes to improvements in dietary quality in rural China. While increasing food accessibility might also increase the consumption of some food that is already overconsumed in rural areas, other policies such as promoting dietary knowledge in rural areas should be implemented along with rural development. Trade can promote a healthier and more balanced diet; Nelson et al. (2018) and Godfray et al. (2010) show that increasing trade always improves the nutrition security of countries. Disputes and conflicts between any two countries can severely disturb global trade and food security. We need to remove obstacles and barriers to facilitate more free trade so that some potential trade opportunities can be used and the demand can be met.

\section{Methods}

Figure 9 presents the flowchart of the methodology. Because people in different agegender groups have different nutritional needs. The population-level nutrient requirement per capita in a country is based on the demographic composition of its population. Countries with a larger aging and female population will have a lower nutrient requirement than those with a younger adult population. The country's demographic composition will change over time, and so will the population-level nutrient and food demand. Based on the dynamic composition of each age-gender population in China, this paper called for the SPCC method (Xiang and Zhong, 2013) to introduce the age-gender structure, urban-rural structure variables to estimate population-weighted average dietary energy requirements. The physical activity level (PAL) and basal metabolic rate (BMR) for different age-gender groups were applied to estimate average dietary energy requirements. 
403

404

405

406

407

408

409

410

411

412

413

414

415

416

417

418

419

420

421

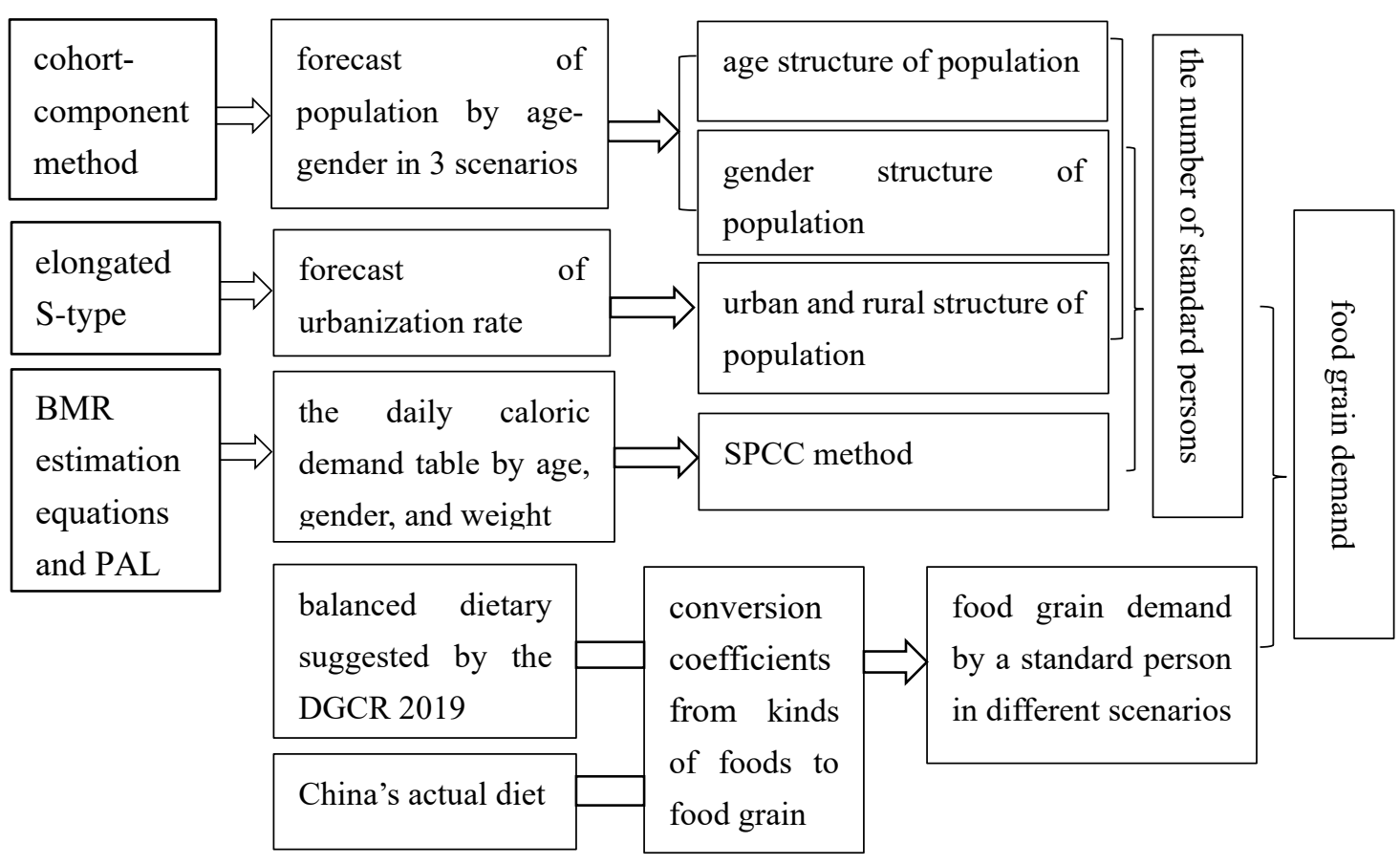

Figure 9. Structural flow diagram of estimating China's food grain demand The following equations show the details of the model.

$\alpha_{\mathrm{ik}}=B M R_{\mathrm{ik}} * P A L_{\mathrm{ik}}$

$\delta_{\mathrm{ik}}=\alpha_{\mathrm{ik}} / \alpha_{17, \mathrm{k}} \quad \mathrm{i}=1,2 \cdots 30$

$y=\frac{1}{1+\lambda e^{-k t}}$

With equation (3), we got,

$\ln \left(\frac{1}{y}-1\right)=\ln \lambda-k t$

Let $\ln \lambda=\beta_{0},-k=\beta_{1}, \ln \left(\frac{1}{y}-1\right)=y^{\prime}$, then equation (4) can be transformed into equation (5).

$y^{\prime}=\beta_{0}+\beta_{1} t$

With China's urbanization rate data during 1978-2020, the linear result obtained by fitting curve is as follows.

$y^{\prime}=1.568-0.048 t+\varepsilon$

To equation (6), at the significance level of $0.05, R^{2}=0.99, \mathrm{~F}=4058.09$ and $t_{1.568}=85.05, t_{-0.048}=-63.70$.

$G_{i j}=\frac{L_{i j *} * V_{i}}{1-C_{i}} \quad(i=1,2, \cdots 9 ; j=1,2,3,4)$

$A G_{j}=\sum_{i=1}^{9} G_{i j} * 365 / 1000$

$s g d_{s}=\sum_{k=1}^{2} \sum_{i=1}^{6} s p_{i k s} * y * u_{k}+\sum_{k=1}^{2} \sum_{i=1}^{6} s p_{i k s} *(1-y) * r_{k}$ 
425 Since we considered multiple factors that drive the change of food grain demand in the forecasting process, we call the model established in this paper the multi-factor driven model. Definitions of all notations are listed in table 10.

Table 10. Definitions of all notations

\begin{tabular}{|c|c|}
\hline$\alpha_{\mathrm{ik}}$ & average daily demand for energy of a person at the age $i$ with gender $k$ \\
\hline$B M R_{\mathrm{ik}}$ & basal metabolic rate of a person at the age $i$ with gender $k$ \\
\hline$P A L_{\mathrm{ik}}$ & physical activity level of a person at the age $i$ with gender $k$ \\
\hline$A W_{\mathrm{ik}}$ & Average weight of a person at the age $i$ with gender $k$ \\
\hline$\delta_{\mathrm{ik}}$ & the standard person consumption coefficient of a person at the age $i$ with gender $k$ \\
\hline$y$ & urbanization rate \\
\hline$y^{\prime}$ & replacement variable of $y$ \\
\hline$t$ & time, we set $\mathrm{t}=0$ in $1978, \mathrm{t}=1$ in $1979, \mathrm{t}=2$ in $1980 \ldots$ \\
\hline $\begin{array}{l}\lambda, \\
k, \beta_{0}, \beta_{1}\end{array}$ & parameters \\
\hline$L_{i j}$ & $\begin{array}{l}\text { the per capita daily food grain demand of } i \text {-th categories of food based on DGCR } \\
2019 \text { in three level of low }(j=1), \text { medium }(j=2) \text { and high }(j=3)\end{array}$ \\
\hline$L_{i 4}$ & actual average per capita daily foods consumption \\
\hline$V_{i}$ & the conversion coefficient of $i$-th categories of food \\
\hline$C_{i}$ & the percentage of food waste in household consumption of $i$-th categories of food \\
\hline$G_{i j}(\mathrm{j}=1,2,3)$ & $\begin{array}{l}\text { the per capita daily } i \text {-th categories of food grain demand by an adult in low, } \\
\text { medium, and high level suggested by DGCR } 2019 \text { respectively }\end{array}$ \\
\hline$G_{i 4}$ & the actual average per capita daily $i$-th categories of food grain consumption \\
\hline$s p_{\mathrm{iks}}$ & the size of standard persons at the age group $i$ with gender $k$ in scenario $s$ \\
\hline$u_{k}$ & the estimated food grain demand of a standard person with gender $k$ in urban area \\
\hline$r_{k}$ & the estimated food grain demand of a standard person with gender $k$ in rural area \\
\hline$g d_{s}$ & if SPCC method was not applied, the food grain demand in scenario $s$ \\
\hline$p_{s}$ & the population size in scenario $s$ \\
\hline$a g d_{s}$ & if the actual dietary structure was kept, the food grain demand in scenario $s$ \\
\hline
\end{tabular}

\section{Data Source}

430 The nutrient requirements are from the DGCR 2019. The value of PAL for different age-gender groups is sourced from FAO (2004), which is the latest reference we can found. According to the data available in the FAO database, the period of 1961 to 2018 is chosen to be studied. Typical diet varies across countries and reflects a country's tradition and culture and natural and land-use conditions. We used the average reported food consumption between 2014 and 2018 (to smooth out fluctuations in any one year) as the baseline for China's typical diet. The weights of males and females aged 0-69 in China are sourced from The 2014 National Physical Fitness Monitoring 438 Bulletin published by the State Sports General Administration ${ }^{6}$. The average weight of 
Chinese males over 70 years old was $63.5 \mathrm{~kg}$, and of Chinese females was $55.6 \mathrm{~kg}(\mathrm{Lv}$ and Zhang, 2018). We chose annual time data because it is appropriate for the production cycle and the time scale of the model (2021-2050). And because data on consumption, production, and population are only available annually.

Acknowledgments This work was supported by grants from the National Nature Science Foundation of China under Grant No. 71874184 and the 2019 Chinese Government Scholarship No. 201904910157.

Author contributions Professor Xiuli Liu designed the model, made the calculation, and drafted the manuscript. Ph.D. candidate Yuxing Dou collected data, some references and forecasted China's urbanization rate. Professor Dabo Guan provided suggestions and edited the manuscript. Professor Geoffrey Hewings reviewed and edited the manuscript. Professor Shouyang Wang explained some results and provided policy implications. All authors contributed to the revisions.

Competing interests The authors declare no competing interests.

Data availability All data used in this study are publicly available from open sources as indicated in the references. Inquiries related to the data should be made to X. L. (xiuli.liu@amss.ac.cn).
Received:24 June 2021; Accepted:
Published online:

\section{References}

1. FAO. The State of Food and Agriculture 1996: Food Security: Some Macroeconomic Dimensions. (FAO, Rome,1996).

2. UN. UN World Population Prospects: The 2017 Revision. https://www.un.org/en/desa/world-population-prospects-2017-revision. (2018).

3. FAO, IFAD, UNICEF, WFP \& WHO. The state of food security and nutrition in the world 2020 (SOFI 2020). (FAO, Rome, 2020).

4. Brown, L. Who will feed China? Wake-up call for a small planet. Int. J. Child. R. 5, 504-506 (1995)

5. Sheng, Y. \& Song, L. Agricultural production and food consumption in China: A long-term projection. China Econ. Rev. 53, 15-29 (2019).

6. Huang, J. \& Rozelle, S. Technological change: Rediscovering the engine of productivity growth in China's rural economy. J. Dev. Econ. 49, 337-369 (1996).

7. Gilland, B. World population and food supply - Can food production keep pace with population growth in the next half-century? Food Policy, 27, 47-63 (2002).

8. Zhang, J. China's success in increasing per capita food production. J. Exp. Bot. 62, 3707-3711 (2011).

9. Peng, X., Shi, Q. \& Zhu, X. The source of China's grain production growth (20002013). Agric. Econ. Probl. 1, 97-109 (2018). (in Chinese)

10. Huang, J., Rozelle, S. \& Rosegrant, M. China's food economy to the twenty-first century: supply, demand, and trade. Econ. Dev Cult Change 47, 737-766 (1999).

11. Chen Y. \& Lu C. Future grain consumption trends and implications on grain security in China. Sustainability 11, 5165 (2019).

12. NBSC. China Rural Statistical Yearbook 2018. (China Statistics Press, Beijing, 2018) 
13. Anderson, K. \& Strutt, A. Food security policy options for China: Lessons from other countries. Food Policy 49, 50-58 (2014).

14. Borlaug, N. \& Dowswell, C. To nourish infertile soil that feeds a fertile population that crowds a fragile world. Fertil. News 38: 11-20 (1993).

15. Conway, G. The Doubly Green Revolution: Food for all in the 21st century. (Penguin, London, 1997).

16. Lobell, D., Burke, M., Tebaldi, C., Mastrandrea, M., Falcon, W. \& Naylor, R. Prioritizing climate change adaptation needs for food security in 2030. Sci 319, 607-610 (2008).

17. Müller, C., Bondeau, A., Popp, A., Waha, K. \& Fader, M. Climate change impacts on agricultural yields. https://openknowledge.worldbank.org/handle/10986/9065. (2009)

18. Rosenzweig, C. et al. Assessing agricultural risks of climate change in the $21 \mathrm{st}$ century in a global gridded crop model intercomparison. Proc. Natl Acad. Sci. USA 111, 3268-3273 (2014).

19. Ge, J. et al. Food and nutrition security under global trade: a relation-driven agentbased global trade model. R. Soc. Open Sci. 8, 201587. (2021).

20. Macdiarmid, J., Clark, H., Whybrow, S., Ruiter, H. \& McNeill, G. Assessing national nutrition security: the UK reliance on imports to meet population energy and nutrient recommendations. Plos One 13, e0192649. (2018)

21. Ruiter, H., Macdiarmid, J., Matthews, R. \& Smith, P. Moving beyond calories and protein: micronutrient assessment of UK diets and land use. Global Environ. Change 52, 108-116. (2018)

22. Nair, M., Augustine, L. \& Konapur, A. Food based interventions to modify diet quality and diversity to address multiple micronutrient deficiency. Front. Public Health 3, 277. (2016)

23. Liu, X. A method to visualize the skeleton industrial structure with input-output analysis and its application in China, Japan and USA. J. Syst Sci Complex, 31, 1554-1570 (2018).

24. Hovhannisyan, V., Mendis, S. \& Bastian, C. An econometric analysis of demand for food quantity and quality in urban China. Agric. Econ. 50, 3-13 (2019).

25. Liu Q. \& Liu X. Forecasting on China's population size and structure during 20182100 with the background of family planning policy adjustment. Math. Pract. Th. 48,180-188 (2018). (in Chinese)

26. Vecchia, C. \& Majem, L. Evaluating trends in global dietary patterns. Lancet Glob. Health 3, e114-e115 (2015).

27. Gouel, C. \& Guimbard, H. Nutrition transition and the structure of global food demand. Am J. Agric. Econ. 101, 383-403 (2019).

28. Liu, X., Chen, X. \& Wang, S. The comparative study on changes of dietary structure among residents in mainland China and other regions. Basic Clin. Pharmacol. Toxicol. 124, 378-379 (2019).

29. Vasileska, A. \& Rechkoska, G. Global and regional food consumption patterns and trends. Procedia-Social and Behavioral Sci. 44, 363-369 (2012). 
30. Popkin, B., Adair, L. \& Ng, S. Global nutrition transition and the pandemic of obesity in developing countries. Nutr. Rev. 70, 3-21 (2012).

31. Han, A., Sun, T., Ming, J., Chai, L. \& Liao, X. Are the Chinese moving toward a healthy diet? evidence from macro data from 1961 to 2017. Int. J. Env. Res. Pub. He. 17,1-13 (2020).

32. Lv, X., Li, L., Liu, M., Wei, S.; Wang, S. \& Fan, D. Comparative analysis of food consumption transformation characteristics of Chinese urban and rural residents from 1984 to 2014. J. Shandong Agric. Univ. 19, 52-58 (2017). (in Chinese)

33. Xin, L. \& Li, P. Food consumption patterns of Chinese urban and rural residents based on CHNS and comparison with the data of national bureau of statistics. $J$. Nat. Resour. 33, 75-84 (2018).

34. Zheng, Z., Gao, Y. \& Zhao, Y. The impact of income growth on the food consumption patterns of urban residents. Economics 15, 263-288 (2016).

35. Zhang, W., Shen, G., Cao, H., Xu, X. \& Wang, H. Major agricultural products consumption trend, influence and policy: during the 13th five-year period. Agric. Econ. Issues 37, 11-17 (2016). (in Chinese)

36. Huang, J. Forty Years of China's Agricultural development and reform and the way forward in the future. Agric. Technol. Econ. 3, 4-15 (2018). (in Chinese)

37. Chen, Z., Guo, Q. \& Jiang, H. Resident Food consumption upgrade and Chinese agricultural transformation. Mod. Econ. Res. 12, 120-126 (2018).

38. Zhang, Y., Tian, Q., Hu, H. \& Yu, M. Water footprint of food consumption by Chinese residents. Int. J. Environ. Res. Public Health 16, 3979 (2019).

39. Li, Y. et al. Potential impact of time trend of life-style factors on cardiovascular disease burden in China. J. Am. Coll. Cardiol. 68, 818-833 (2016).

40. Gerbens-Leenes, P. \& Nonhebel, S. Consumption patterns and their effects on land required for food. Ecol. Econ. 42, 185-199 (2002).

41. Hovhannisyan, V. \& Gould, B. Structural change in urban Chinese food preferences. Agric. Econ. 45, 159-166 (2014).

42. Hovhannisyan, V. \& Devadoss, S. Effects of urbanization on food demand in China. Empir. Econ. 58, 1-23 (2017).

43. Cheng, G. \& Chen, L. The long-term trend of China's grain demand. China Rural Surv. 3, 1-5 (1998). (in Chinese)

44. Ma, Y. \& Niu, W. Forecasting on grain demand and availability of cultivated land resources based on grain safety in China. China Soft Sci. 3,11-16 (2009). (in Chinese)

45. Xin, L., Wang, J. \& Wang L. Prospect of per capita grain demand driven by dietary structure change in China. Resour. Sci. 37, 1347-1356 (2015). (in Chinese)

46. Wu, L. Study on long-term trends in China's grain demand. (Huazhong Agricultural University, 2011).

47. Xiang, J. \& Zhong, F. Impact of demographic transition on food demand in China: 2010-2050. China Popul. Resour. Environ. 23, 117-121 (2013). (in Chinese)

48. Liu, H. \& Chen, Y. Influence of population structure change on China's grain demand and its countermeasures. Farmer's Daily 4,16 (2016). 
49. Luo, J. Study on grain consumption based on the goal of nutrition. (Chinese Academy of Agricultural Science, 2008). (in Chinese)

50. Tang, H. \& Li, Z. Study on per capita grain demand based on Chinese reasonable dietary pattern. Sci. Agric. Sin. 45, 2315-2327 (2012). (in Chinese)

51. Xiang, J. \& Zhong, F. Impact of demographic transition on food demand in China: 2010-2050. China Popul. Resour. Environ. 23, 117-121 (2013).

52. FAO. Human energy requirements. Report of a Joint FAO/WHO/UNU Expert Consultation. https://www.who.int/nutrition/publications/nutrientrequirements/9251052123/en/. (2004).

53. Lv, J. \& Zhang, H. Selection and Measurement of Physical Fitness Evaluation Indicators for 70 79 Year Old People. Sichuan Sports Sci. 37, 34-36 (2018). (in Chinese)

54. Schofield, W. Predicting basal metabolic rate, new standards and review of previous work. Hum. Nutr. Clin. Nutr. 39, S5-S41 (1985).

55. Henry, C. Basal metabolic rate studies in humans: measurement and development of new equations. Public Health Nutr. 8,1133-1152 (2005).

56. Jian, X. \& Huang, K. Empirical analysis and forecast of the level and speed of urbanization in China. Econ. Res. J. 45, 28-39 (2010).

57. Zeng, Y. Continue to promote late childbearing and gradually relax the current fertility policy. (Social Sciences Academic Press (CHINA), Beijing, 2013).

58. The Rural Development Research (RDR) Institute of Chinese Academy of Social Science. China Rural Development Report 2020 (China Social Sciences Press, Beijing, 2020).

59. Institute of Urban Development and Environment (UDE,2019) of the Chinese Academy of Social Sciences. The Urban Blue Book: Annual Report on Urban Development of China No. 12. (Social Sciences Academic Press (CHINA), Beijing, 2019). (in Chinese)

60. Gustavsson, J., Cederberg, C., Sonesson, U., Otterdijk, R. \& Meybeck, A. Global food losses and food waste. (FAO, Rome, 2011).

61. Chinese Nutrition Society. Chinese DRIs Handbook (2013). (China Standards Press, Beijing, 2014). (in Chinese)

62. Xinhua Net. $35 \%$ of China's annual food production is wasted, 70 billion kilograms of waste off the table. http://www.chinanews.com/gn/2014/10-19/6693205.shtml. (2014).

63. Cheng, S.K., Jin, Z.H., Liu, G. Report on Food Waste in Urban Restaurants in China, Beijing (2018).

64. Lv, X. \& Hu, F. Forecasting and countermeasure on China's grain supply and demand in 2020. Iss. Agric. Econ. 10, 11-19 (2012).

65. Mi, J., Luo, Q. \& Gao, M. A review on food demand forecast methods. Chin. J. Agric Resour. Reg. Plan. 34, 28-33 (2013).

66. Gao, Q. Analysis and forecast of food consumption of urban and rural residents. Chin. Rural Econ. 10, 20 -25+32 (2004). (in Chinese) 
67. Yuan, Y., Song, J., Yang, C. \& Liu, A. Balanced diets food from the angle of demand forecasting. Chin. J. Agric. Resour. Reg. Plan. 38, 119-123 (2017). (in Chinese)

68. Zhang, Y., Li, Z., Li, Z. \& Xu S. China grains demand forecast analysis based on china economy-wide multi-market model. Food Nutr. China 18, 40-45 (2012). (in Chinese)

69. Ye, L. et al. Climate change impact on China food security in 2050. Agron. Sustain. Dev. 33, 363-374 (2013).

70. Tian, Z. et al. The potential contribution of growing rapeseed in winter fallow fields across Yangtze River Basin to energy and food security in China. Resour. Conserv. Recy. 164, 105-159 (2021).

71. Nelson, G. et al. Income growth and climate change effects on global nutrition security to mid-century. Nat. Sustain. 1, 773-781 (2018) .

72. Godfray, H. et al. Food security: the challenge of feeding 9 billion people. Sci.327, 812-818 (2010).

73. Fuchs, R., Alexander, P., Brown, C., Cossar, F., Henry, R. \& Rounsevell, M. Why the US-China trade war spells disaster for the Amazon. Nature 567, 451-454 (2019).

74. Challies, E., Newig, J. \& Lenschow, A. What role for social-ecological systems research in governing global teleconnections? Global Environ. Change 27, 32-40 (2014).

75. Qian, Y., Liu, X.Y., Fang, B., Zhang, F. and Gao, R., Investigating fertility intentions for a second child in contemporary China based on user-generated content, Int. J. Environ. Res. Public Health 17, 3905 (2020).

76. Li, X., Fan, Y., Assanangkornchai, S., McNeil, E.B. Application of the theory of planned behavior to couples' fertility decision-making in Inner Mongolia, China. PLoS ONE 14 (2019). 